\title{
An Assessment of Schools' Efficiency of Different Educational Systems
}

\author{
Montserrat Casalprim \\ Josep Rialp \\ Diego Prior
}

Betlem Sabrià

Doi:10.5901/mjss.2013.v4n11p631

\begin{abstract}
The allocation of public resources is an important concern of developed economies in modern societies and there are many studies that aim at measuring their efficiency. This work presents an efficiency assessment of public elementary schools in Andorra, a little country where there are three public educational systems (Andorran, Spanish - congregational and non congregational-, and French). Therefore, the aim of this study is to compare the efficiency of public elementary schools among the three different educational systems existing in Andorra. The methodology used to measure the efficiency of the educational process in this study is the DEA (Data Envelopment Analysis), a nonparametric frontier method, introduced by Charnes, Cooper and Rhodes in 1978. In this study the DEA technique is applied with bootstrap (Simar and Wilson, 2000), that correct the bias by generating successive evaluations with changed data in order to obtain a new distribution of efficiency levels representative of the original (correct but unknown) distribution. Then two nonparametric tests are used (median test and Kruskal-Wallis test) to establish the comparison of efficiency results between different educational systems and identify which system is the most efficient.Results show a decreasing of efficiency along the years and suggest that there are significant differences between different centres depending on their educational system. These results seem to confirm the benefits of decentralization in efficiency of schools.
\end{abstract}

Keywords: DEA, efficiency, bootstrap, production function, education, academic performance, public resources.

\section{Introduction}

Adam Smith starts the discussion on the role of state in the economy with his work Wealth of Nations, in 1776. The development of the welfare economy and the current context, with an increasing national debt in the developed economies, has generated new lines of discussion about the efficiency of public services.

The measurement of the profitability of the public sector as a supplier of public services is difficult; particularly, in the field of education several attempts have been observed in the literature to do it. The estimation of efficient frontiers opens the possibility of detecting inefficient situations. This means that we can improve the performance of the public sector without increasing the resources assigned (output orientation) or that we can maintain performance of the public sector even if we reduce public resources (input orientation). Furthermore, the question of efficiency gives a new dimension to the current debate on the size of the state (Afonso and Aubyn, 2005).

Farrell opened the studies of organization's efficiency in 1957 using the concept of "Pareto efficiency". From this perspective, the most efficient organization is one that carries out like the best and even better. Given that the concept of efficiency is closely related to productivity, which establishes the relationship between inputs and outputs, the organization with the highest productivity in all inputs will be the most efficient one. With this information, it is possible to calculate the percentage of inefficiency of the other organizations compared to one the most efficient one.

When there are multiple inputs and multiple outputs, there appears the concept of "overall productivity". Early indicators appeared in a paper by Charnes, Cooper and Rhodes published in 1978. They propose to do a weighted sum of all inputs and all outputs and the ratio of the two sums. The weightings are the prices and the result is the ratio of income and expenses (Profitability). If the ratio is $>1$ means there are benefits; if the ratio is $=1$ means the benefit is zero; and if the result is $<1$, there are losses. When there are not prices for inputs, or for outputs, the solution proposed is to calculate the weights that maximize the ratio above with two constraints:

1. The weightings cannot tend to infinity.

2. It is necessary to apply the same weights to all units so that the sum is $\leq 1$. 
If these two constraints are introduced to maximize the function, the best unit has a value $=1$ and all the rest must be $<1$.

This is how the DEA method (Data Envelopment Analysis) has been developed. This method draws the frontier of efficient DMUs (Decision Making Units) that act better than the rest, and measures the distance to the rest of the frontier. This method allows us to measure efficiency in organizations where there are multiple inputs and outputs, whose prices are unknown. Mainly, it is for this reason that it is an appropriate method to measure the efficiency of educational process.

The main objective of this study is to analyze the efficiency of elementary schools in Andorra, identifying the variables involved in this process. Some previous studies that followed this general objective in elementary level schools are: Bessent and Bessent (1980), in a Californian urban district; Kim et al. (2006), in New York City; Conroy and Arguea (2008), in Florida; Addonizio (2009), in Minnessota; and Barbosa and Wilhelm (2009), in Paraná; and Thieme et al. (2011) in Chile. The particular environment in Andorra, with three public educational systems (Andorran, Spanish and French), provide a new context to apply efficiency studies of educational process and results of this study can give new contributions to existent literature in this field.

\section{Educational Context in Andorra}

Andorra is a small country of $468 \mathrm{~km}^{2}$ with 78,115 inhabitants ${ }^{1}$ where there are three different educational systems: Andorran, French and Spanish. Regarding at Spanish educational system, must distinguish between the Spanish public schools, private schools and public congregational schools. This study was carried out in all Andorran public schools, excluding one school belonging to the private Spanish educational system, but including congregational schools, which are financed, like schools of the Andorran educational system, by the Andorran Government. It is for this reason that four educational systems are considered: a) Andorran, b) Spanish public, c) Spanish congregational and d) French.

Considering elementary levels (from 3 to 12 years old, for Andorran and Spanish systems, and from 3 to 11 years old for French system), there were 25 schools (8 from the Andorran educational system, 5 from the public Spanish educational system, 3 from the congregational Spanish educational system and 9 from the French system) during five academic years (from 2005-6 until 2009-10). In June 2011, according to data provided by the head of the school, there were 6.663 children at elementary level (2832 in the Andorran educational system, 527 in the Spanish educational system, 1,342 in the Spanish congregational educational system and 1,962 in the French educational system).

One of the main features that distinguish the four systems is the vehicular language or languages used, in addition, of course, of the specificities of the official curriculum for each system. In the Andorran system, the vehicular languages are Catalan and French. There are two permanent teachers in the classroom (one Catalan-speaking and one French-speaking). In the Spanish non-congregational system, the vehicular language is Spanish; French is taught as a foreign language, just like English. In the Spanish congregational system, the vehicular language is Catalan; Spanish is taught more intensively than the other languages; French and English are taught as foreign languages. In the French system, the vehicular language is French; Spanish and English are taught as foreign languages. Moreover, the educational agreement between Andorra and neighbouring states establishes that it is necessary to include two subjects in the curricula of all systems: Catalan and Andorran history.

Another important difference between the four systems is the level of autonomy in school management, especially in the recruitment process of teachers. In Andorran and french systems, the process is centralized by the national government of each country, and teachers hired achieve the working place in Andorra for a long time. In Spanish noncongregational system hiring process is also centralized by the Spanish government, but it is a temporal hiring: places are offered to existing Spanish teachers, that have yet a place in a Spanish school and want to change the place for a limited period (maximum 6 years). After this period, teachers have to leave Andorra and return to the originally Spanish school. Is for this reason that teachers rotation is bigger in schools of the Spanish non-congregational educational system. The most different recruitment process of teachers in Andorra is in schools of Spanish congregational system, where is decentralized and is the principal of each school the responsible of the process. The school calendar is set by the Andorran Government and it is the same for all schools regardless of the educational system to which they belong. There is also the same number of teaching hours in the schedule of all schools. While it is true that the evaluation system has some specificities for each system, like qualification system, all the systems apply the same criteria to determine if a student can move up to the next course, as has been confirmed in interviews with the heads of the three educational

${ }^{1}$ Source: web of national andorran statistics institute (www.estadistica.ad) 
systems.

In Andorra there is no common test for all educational systems and it is a country out of the Pisa project, at this moment. No data are available that provide homogeneous academic results in order to compare the different educational systems. It is for this reason that when we need an indicator of academic results we will use the number of students that move up to the next course.

With regard to funding, the Andorran educational system and the Spanish congregational system are fully financed by the Andorran Government. The Andorran Government also finances infrastructure, facilities, teaching assistants and training in Andorran subjects (Catalan and Andorran history) of all schools in the country. The Spanish noncongregational and the French educational systems are financed by the governments of their respective countries (Spain and France).

The Andorran educational system emerged in 1980. Before then, public education in Andorra was offered by educational systems of neighbouring countries and the Andorran Government contributed with the two subjects mentioned above (Catalan and Andorran history). Public data in the web of national Andorran statistics institute (www.estadistica.ad) show a decrease of elementary students in Andorra in the last years (2004-2011). There has been a decrease of population in Andorra during this period. This decrease of students $(-2,6 \%)$ has been more important in Spanish non-congregational educational system (-37,57\%). French educational system has also had a decrease of students, with a $-11,15 \%$ of variation, but Andorran and Spanish congregational educational systems have increased their students with a 12,05\% and a 3,86\% respectively. The Spanish non-congregational educational system in recent years has closed two elementary schools.

\section{Methodology}

The particularities of the educational process are different from those characterizing other productive processes. The educational process is a multi-input and multi-output very complex production process whose prices are unknown. Another particularity of the educational processes is that there is not a clear productive function to describe it.

There are different methods used in the literature to measure the efficiency of educational process. Some of these methods are parametric, like regression analysis (Gray et al., 1986; Jesson et al., 1987) or Cobb Douglas function production (Henderson and Quandt, 1971) or the Stochastic Frontier Analysis (SFA) method (Aigner et al., 1977; Meeusen and van den Broeck, 1977; Franta and Konecny, 2009). Other methods used in the literature revised are nonparametric, like the Free Disposable Hull (FDH) method (Thieme et al., 2011; Lavado and Cabanda, 2009; Agasisti, 2009; Afonso and Aubyn, 2006; and Oliveira and Santos, 2006), and Data Envelopment Analysis (DEA).

DEA is a non-parametric frontier method that designs the best weight for each input and output in order to obtain the best efficiency measure for each unit (for each Decision-Making Unit: DMU). It can work, then, without prices for inputs and outputs. This method is also useful if there are multiple inputs and outputs, and it allows identifying the inefficiency causes through peer comparison. DEA compares each DMU with the nearest one in the frontier and measures the distance to the frontier. This distance shows the reduction of inputs (input orientation) or the increase of outputs (output orientation) that each non-efficient DMU can achieve to become efficient (to be at the frontier). DEA was introduced by Charnes, Cooper and Rhodes in 1978. Focused on educational process, previous studies that have used this methodology are: Chen and Chen, 2011; Afonso et al., 2010; Naper, 2010; Chang et al., 2009; Tyagi et al., 2009; Barbosa and Wilhelm, 2009; Lavado and Cabanda, 2009; Agasisti, 2009; Cordero et al., 2009; Kao and Hung, 2008; Johnes and Yu, 2008; Murias et al., 2008; Manzebón and Muñiz, 2008; Ray and Jeon, 2008; Spircu et al., 2007; Giménez et al. 2007; Afonso and Aubyn, 2006; Portela and Thanassoulis, 2001; Thanassoulis, 1996.

DEA method constructs the production frontier that envelops the set of observation using linear programming methods. Afonso et al. (2010) describe the linear programming for an input-orientation with variable-returns to scale by this form:

$\operatorname{Min} \delta, \lambda \delta$ i

s. t. $-y_{i}+Y \lambda \geq 0$

$\delta x_{i}-X \lambda \geq 0$

$n 1^{\prime} \lambda=1$

$\lambda \geq 0$

Where there are $k$ inputs, $m$ outputs and $n$ DMUs, and:

$\mathrm{i}$ is the DMU under assessment

$x_{i}$ is the column vector of the inputs 
$y_{i}$ is the column vector of the outputs

$\mathrm{X}$ is the $(k \times n)$ input matrix

$Y$ is the $(m \times n)$ output matrix

$\delta$ is a scalar that satisfies $\delta \leq 1$. More specifically, it is the efficiency score that measures the distance between a $\mathrm{DMU}$ and the efficiency frontier, defined as a linear combination of the best practice observations.

With $\delta<1$, the DMU is inside the frontier (i.e. it is inefficient),

While $\delta=1$ implies that the DMU is on the frontier (i.e. it is efficient)

$\lambda$ is a $(n \times 1)$ activity vector that measures the weights used to mix the efficient units taken as a benchmark of the unit under assessment.

1 is an n-dimensional vector of ones.

The inefficient DMU is projected on the production frontier. The frontier is composed of efficient units and their lineal combination.

The restriction $n 1^{\prime} \lambda=1$ imposes a technology exhibiting variable returns to scale (VRS). Dropping this restriction implies that constant returns to scale are prevalent.

The previous mathematical program has to be solved $n$ times, one for each DMU in the analysis.

In order to design the frontier with the DMUs that have shown the best practice DEA with input orientation is used, considering variable returns to scale (VRS) with 2 inputs $\left(X_{1}\right.$ and $\left.X_{2}\right)$ and 2 outputs. Figure 1 provides a graphical intuition of the analysis performed.

Figure 1. Efficiency frontier input oriented

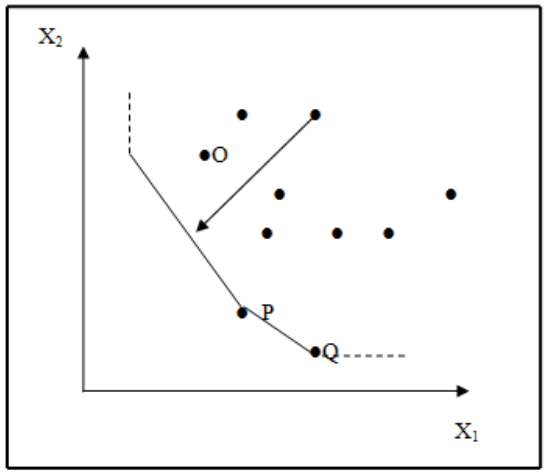

A contemporary DEA for 5 academic years (from 2005-6 to 2009-10) is applied considering 25 DMUs per year (the 25 public elementary schools) so the analysis considers the data year by year, not pooling them. In order to increase the number of units, an intertemporal DEA is also applied pooling the data from all the years (considering 125 DMUs and interpreting the same school in different years as different DMUs).

In the second step, the intertemporal DEA estimation is bootstrapped (Simar and Wilson, 2000) in order to correct the potential bias in the original estimations. Bootstrap technique with DEA is introduced by Simar and Wilson (2000) and has been used by others, like Blank and Van Hulst, 2011; Murillo et al., 2010; Oliveira and Santos, 2005; and Fuentes, 2011.

Finally, two nonparametric tests (Median test and Kruskal-Wallis test) are used to establish the comparison of efficiency results between different educational systems. These methods allow us to test differences between groups (educational systems in this study) by comparing the medians and the mean ranks respectively. Both methods are useful when the normality distribution assumption is not guaranteed.

\section{Data}

As it is exposed above, most of educational data are not available in Andorra. There is just a data used in this study that is public: the total number of students per year. This data is published by the National Statistic Service of the Government of Andorra (www.estadistica.ad).

The rest of data were provided by the Ministry of Education of the Government of Andorra. To get the authorisation 
to obtain these data it is has been necessary to sign a confidentiality commitment in which we agree to identify anonymously the different schools in the results of the study. Therefore, we identify the four educational systems (with the terms: $A, B, C$ and $D$, and the different schools by numbers (from 1 to 125 ).

\subsection{Inputs}

Two general inputs are identified in the literature on schools efficiency: financial and human resources. The most usual indicators for each of these inputs are: operating expenses and academic staff, respectively.

Operating expenses (we will tell this variable Opex) has been used as an input in educational process efficiency studies by Casu and Thanassoulis, 2006; Kim et al., 2006; Kao and Hung, 2008; Yuhong and Yongmei, 2008; Addonizio, 2009; and Tyagi et al., 2009, among others.

Moreover, academic staff (we will tell this variable Teachers) has been used as an input in educational process efficiency studies by Kantabutra and Tang, 2006; Kim et al., 2006; Martín, 2006; Giménez et al., 2007; Spircu et al., 2007; Conroy and Arguea, 2008; Yuhong and Yongmei, 2008; Cordero et al., 2008; Addonizio, 2009; Agasisti, 2009; Cheo, 2009; Franta and Konecny, 2009; Tyagi et al., 2009; Naper, 2010; Ouellette and Vierstraete, 2010; Chen and Chen, 2011; and Thieme et al., 2011, among others.

\subsection{Outputs}

The difficulty in measuring the outputs of the educational process, such as the positive effects of education on economic and social development of a society focused most efficiency studies of education in more easily measurable outputs. It is for this reason that attempts to measure the efficiency of the schools is limited to internal efficiency, which considers only the relationship between inputs and measurable outputs schools.

It is difficult to define the social value of education. Additionally educational outputs don't have market prices and it is difficult to identify their value. As shown in Shields and Shields(2009), education has a. direct impact on the overall country's equity, as there are positive externalities of education, which are long-term and difficult to measure. Afonso et al. (2010) studied the impact of the quality of education in the efficiency of public resources for equality in several OECD countries and found that the efficiency of social spending is more enhanced by the success of education than to the education spending.

The most frequent outputs in the literature .are the academic results in a global test (maths and reading or language), as Hanushek (1997) has shown in a literature review. This test is passed to all the students at the end of some school level.

In Andorra does not exist a homogeneous test for all the students of the different educational systems, so it is not possible to choose this indicator as an output to our study. We take the number of students that moved up to the next course successfully as an indicator of academic results. We will name this variable Passstudents. The same indicator is used by Oliveira and Santos, 2005; Spircu et al., 2007; Mancebón and Muñiz, 2008; Cordero et al., 2008; Che0, 2009; and Barbosa and Wilhelm, 2009, among other.

The second output used in this study is a measure of the number of students (Students). This output has been used by Martín, 2006; Kao and Hung, 2008; Tyagi et al., 2009; Ouellette and Vierstraete, 2010, among others.

\section{Results}

Results of contemporary study (25 DMUs per year, 5 frontiers -one for each year-) show a slight decrease in efficiency measures over the years and the same 5 schools appear at the frontier over the years. This result serves to confirm the consistency of the frontier along the years. These 5 schools belong to two different educational systems $(C$ and $D)$ and those used as peers for more inefficient DMUs are from educational system $C$. Another result is the presence of the same school with the lowest efficiency score every year, belonging to the educational system B. Again another signal of consistency.

Results of the intertemporal study (125 DMUs considering all 5 years together) show a decrease in efficiency scores during the 2008-2009 period. This period was also the first with a decrease in the Andorran population and in the number of students in the elementary grade. Efficiency scores of these $125 \mathrm{DMUs}$ also show one school belonging to the educational system $C$ that appears every year at the frontier (DMU14, DMU39, DMU64 DMU89 and DMU114). In table 1 we can observe that this school, during the first academic year analysed is the most used as a benchmark for other 
DMUs and every year is used less as a benchmark, as the other schools at the frontier. There are 4 more schools, 2 belonging to the educational system $C$ and 2 belonging to the educational system $D$, which appeared different times at the frontier. The school with the lowest score is the same in different years and belongs to the educational system $B$. Overall the intertemporal results depicts a similar assessment than the one produced with the contemporary estimation. Table 1 resume these results.

Table 1. Efficiency results with an intertemporal DEA methodology (125 DMUs: the 25 elementary schools in Andorra from 2005 to 2010)

\begin{tabular}{|c|c|c|c|c|c|}
\hline \multirow{4}{*}{$\begin{array}{c}\text { Efficiency } \\
\text { scores }\end{array}$} & Min. & Max. & Mean & St.Dev. \\
\cline { 2 - 6 } & Global & 0,59 & 1 & 0,83 & 0,110 \\
\cline { 2 - 6 } & Ed. System A & 0,76 & 1 & 0,85 & 0,063 \\
\cline { 2 - 6 } & Ed. System B & 0,59 & 1 & 0,72 & 0,097 \\
\cline { 2 - 6 } & Ed. System C & 0,87 & 1 & 0,98 & 0,041 \\
\cline { 2 - 5 } & Ed. System D & 0,61 & 1 & 0,82 & 0,110 \\
\hline & DMUs & Educational System & Academic Year & Benchmarks \\
\cline { 2 - 5 } & DMU14 & C & $2004-2005$ & 84 \\
\cline { 2 - 5 } & DMU15 & C & $2004-2005$ & 34 \\
\cline { 2 - 5 } & DMU16 & C & $2004-2005$ & 29 \\
\cline { 2 - 5 } & DMU19 & D & $2004-2005$ & 9 \\
\cline { 2 - 5 } & DMU23 & D & $2004-2005$ & 45 \\
\cline { 2 - 5 } & DMU33 & A & $2005-2006$ & 2 \\
\cline { 2 - 5 } & DMU39 & C & $2005-2006$ & 8 \\
\cline { 2 - 5 } & DMU48 & D & $2005-2006$ & 32 \\
\cline { 2 - 5 } & DMU58 & A & $2006-2007$ & 1 \\
\cline { 2 - 5 } & DMU64 & C & $2006-2007$ & 2 \\
\cline { 2 - 5 } & DMU89 & C & $2007-2008$ & 4 \\
\cline { 2 - 5 } & DMU90 & C & $2007-2008$ & 4 \\
\cline { 2 - 5 } & DMU110 & B & $2008-2009$ & 2 \\
\cline { 2 - 5 } & DMU114 & C & $2008-2009$ & 14 \\
\cline { 2 - 5 } & DMU115 & C & $2008-2009$ & 6 \\
\cline { 2 - 5 } & DMU123 & D & $2008-2009$ & 15 \\
\hline
\end{tabular}

Just for controlling the potential bias in the deterministic frontier and for solving dimensionality problems, a second analysis was performed through the bootstrapping estimation method. To do this, FEAR software is used to apply the intertemporal DEA technique with bootstrap (Simar and Wilson, 2000). Generating successive evaluations with changed data in order to obtain a new distribution of efficiency levels representative of the original (correct but unknown) distribution it is possible to correct the potential bias.

We organise efficiency scores and we find the most efficient DMUs: DMU16, DMU41, DMU19, DMU64, DMU39, DMU14, DMU89, DMU44, DMU114. All of them are from educational system C, except two (DMU19 and DMU44), that are the same school of educational system $D$, in different years. This confirms that the $C$ systems appears to be the most efficient independently of the estimation method employed. Table 2 resumes these results.

Table 2. Bootstrapped efficiency results with an intertemporal DEA methodology (125 DMUs: the 25 elementary schools in Andorra from 2005 to 2010).

\begin{tabular}{|c|c|c|c|c|c|c|}
\hline & & & Min. & Max. & Mean & St.Dev. \\
\hline \multirow{5}{*}{\multicolumn{2}{|c|}{ Bootstrapped Efficiency scores }} & Global & 0,57 & 0,98 & 0,79 & 0,10 \\
\hline & & Ed. System A & 0,70 & 0,92 & 0,82 & 0,05 \\
\hline & & Ed. System B & 0,57 & 0,90 & 0,70 & 0,08 \\
\hline & & Ed. System C & 0,85 & 0,98 & 0,92 & 0,04 \\
\hline & & Ed. System D & 0,59 & 0,96 & 0,78 & 0,10 \\
\hline \multirow{5}{*}{ Confidence Interval } & \multirow{5}{*}{ Lower bound } & & Min. & Max. & Mean & St.Dev. \\
\hline & & Global & 0,58 & 1 & 0,82 & 0,11 \\
\hline & & Ed. System A & 0,76 & 0,99 & 0,85 & 0,06 \\
\hline & & Ed. System B & 0,58 & 0,99 & 0,72 & 0,10 \\
\hline & & Ed. System C & 0,87 & 1 & 0,97 & 0,04 \\
\hline
\end{tabular}




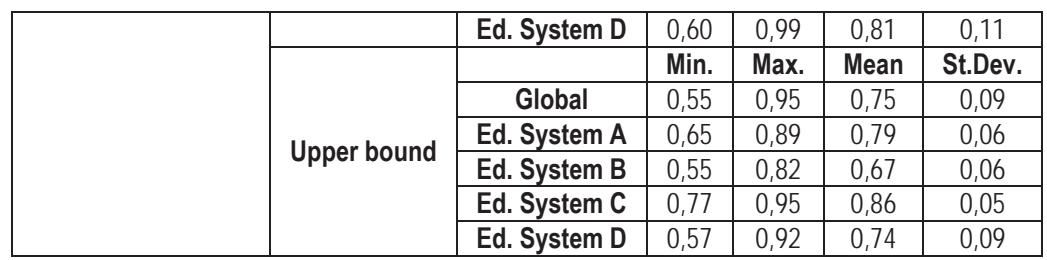

To establish the comparison between different Educational Systems we used two non-parametric methods. The results of these methods are illustrated in table 3.

Median test confirms that there are significant differences in median scores of efficiency between Educational Systems. Schools of Educational System C have a higher median value than schools of other Educational Systems, and schools of Educational System B have a lower median value.

Kruskal-Wallis test confirms that there are significant differences in efficiency between Educational Systems by comparing ranks of the original values.

Table 3. Non-parametric tests to establish the comparison of efficiency between different Educational Systems

\begin{tabular}{|c|l|c|}
\hline \multirow{5}{*}{ Median test } & Median & 0,800025608 \\
\cline { 2 - 3 } & Chi-Square & 37,077 \\
\cline { 2 - 3 } & Degree of freedom & 3 \\
\cline { 2 - 3 } & Asymptotic Significance & 0,000 \\
\cline { 2 - 3 } & & Educ. System A: $58 \%$ \\
& Educ. System B: $: 4 \%$ \\
& & $\begin{array}{c}\text { Educ. System C: } 100 \% \\
\text { Educ. System D: } 51 \%\end{array}$ \\
\hline \multirow{5}{*}{ Kruskal-Wallis test with efficiency scores > median } & 54,664 \\
\cline { 2 - 3 } & Chi-Square & 3 \\
\cline { 2 - 3 } & Degree of freedom & 0,000 \\
\cline { 2 - 3 } & Asymptotic Significance & Educ. System A: 73,28 \\
& & Educ. System B: 27,84 \\
& Mean Rank & $\begin{array}{c}\text { Educ. System C: } 111,40 \\
\text { Educ. System D: } 57,27\end{array}$ \\
\hline
\end{tabular}

\section{Summary and Conclusions}

In a society focused in the problem of public debt, the study of efficiency in public resources allocation is an important concern.

Literature about efficiency of educational process is extensive and show the DEA methodology as a nonparametric frontier method very appropriate to analyse the efficiency of this process, due to their particularities (there are multiple inputs and outputs and their prices are unknown).

This study analyses the efficiency of 25 elementary schools in Andorra, during 5 years, with a contemporary and an intertemporal study, using DEA and applying a bootstrap technique to correct the potential bias.

Considering the 4 different public educational systems that exist in Andorra (Andorran, French, Spanish noncongregational and Spanish congregational), this study makes also a comparison between different educational systems, using nonparametric methods to compare the median values or the mean ranks.

Conclusions that can be drawn from the results of this study are:

1. A decreasing in the efficiency of schools along the years possibly due to the decreasing of Andorran population and of elementary students.

2. A significant difference between educational systems exists. It is shown that the educational system $\mathrm{C}$ has the higher median efficiency value and the higher mean efficiency rank value, and the educational system $B$ has the lower values. Causes of these differences may be analysed but these results suggest us to identify the autonomy in school management, which is a feature of educational system $\mathrm{C}$ that differs from the others, as a positive contribution in efficiency, and stability of staff during the time, that is not a feature of educational system B, as another positive contribution in efficiency.

These results confirm extensive literature that suggests a positive contribution of decentralization in educational outcomes. Some examples are Wößmann (2003), Eskeland and Filmer (2007) and Clark (2005). In the field of efficiency 
of schools, Naper (2010) studies the impact of decentralization in school's efficiency and he concludes that efficiency of schools is higher in districts where hiring is decentralized.Agasisti (2009) suggest the same contribution of decentralization.

This confirms the intuition that, in the same physical environment, the system has a significant impact on the performance of the students. Therefore, it is not the same to enrol a student in one school of $\mathrm{C}$ system than in a school of B system because the school will have a significant impact on the students' result: an important message for the family and for the policy makers in Andorra.

Finally, and anticipating future research work, it is worth to point out that these results need to be contrasted by introducing other factors, for example environmental ones, that could have an effect in efficiency of educational process and that are not considered in this study. As Coleman report (Coleman et al., 1966) shows, the environmental variables role in educational process is truly important. That is the reason why several studies are considering these variables in efficiency measures. Future research will introduce the effect of environmental variables.

\section{References}

Addonizio, M. F. (2009). X-efficiency and effective schools: A new look at old theories. Journal of Education Finance, 35(2), 1-25.

Afonso, A., \& Aubyn, M. (2005). Non-parametric approaches to education and health efficiency in OECD countries. Journal of Applied Economics, 8(2), 227-244. Retrieved from http://search.proquest.com/dociew/233257010?accountid=132760

Afonso, A., Schuknecht, L., \& Tanzi, V. (2010). Income distribution determinants and public spending efficiency. The Journal of Economic Inequality, 8(3), 367-389.

Agasisti, T. (2009). Performances and spending efficiency in higher education: A european comparison through non-parametric approaches. Education Economics, 1, 1-26.

Aigner, D. J., Lovell, C. A. \& Schmidt, P. (1977). Formulation and Estimation of Stochastic Frontier Production Functions. Journal of Econometrics 6, 21-37.

Anderson, T., Daim, T., \& Lavoie, F. (2007). Measuring the efficiency of university technology transfer. Technovation, 27, 306-318.

Barbosa, S. G., \& Wilhelm, V. E. (2009). Evaluation of the performance of public schools through data envelopment analysis. Acta Scientiarum / Technology, 31(1), 71-79.

Bessent, A. M., \& Bessent, E. W. (1980). Determining the comparative efficiency of schools through data envelopment analysis. Educational Administration Quarterly, 16(2), 57-75.

Blank, J. L. T., \& van Hulst, B. L. (2011). Governance and performance: The performance of dutch hospitals explained by governance characteristics. Journal of Medical Systems, 35(5), 991-999.

Casu, B., \& Thanassoulis, E. (2006). Evaluating cost efficiency in central administrative services in UK universities. Omega : The International Journal of Management Science, 34(5), 417.

Chang, D., Wu, C., Ching, G. S., \& Tang, C. (2009). An evaluation of the dynamics of the plan to develop first-class universities and toplevel research centers in taiwan. Asia Pacific Education Review, 10(1), 47-57.

Charnes, A., Cooper, W., \& Rhodes, E. (1978). Measuring the efficiency of decision making units. European Journal of Operational Research, 2(6), 429-444.

Chen, J., \& Chen, I. (2011). Inno-qual efficiency of higher education: Empirical testing using data envelopment analysis. Expert Systems with Applications, 38(3), 1823-1834.

Cheo, R. K. (2009). Ranking and school autonomy: Efficiency effects of new initiatives on the singapore education system. The Singapore Economic Review, 54(2), 197-215.

Clark, D. (2005). Politics, markets and schools: Quasi-experimental evidence on the impact of autonomy and competition from a truly revolutionary UK reform. Oxford: WP Nuffield College.

Coleman, J.S. et al. (1966). Equality of Educational Opportunity (U.S. Office of Education). Washington, DC: U.S. Government Printing Office.

Conroy, S. J., \& Arguea, N. M. (2008). An estimation of technical efficiency for florida public elementary schools. Economics of Education Review, 27(6), 655-663.

Cordero Ferrera, J. M., Pedraja Chaparro, F., \& Salinas Jimenez, J. (2008). Measuring efficiency in education: An analysis of different approaches for incorporating non-discretionary inputs. Applied Economics, 40(10), 1323-1339.

Cordero, J. M., Pedraja, F., \& Santín, D. (2009). Alternative approaches to include exogenous variables in DEA measures: A comparison using monte carlo. Computers \& Operations Research, 36(10), 2699-2706. doi:DOI: 10.1016/j.cor.2008.11.019

Eskeland, G. S., \& Filmer, D. (2007). Autonomy, participation and learning: Findings from Argentine Schools, and implications for decentralization. Education Economics, 15(1), 103-127.

Farrell, M. (1957). The measurement of productive efficiency. Journal of the Royal Statistical Society, Series A,General, 120(Part 3), 253-281.

Franta, M., \& Konecny, T. (2009). Stochastic frontier analysis of the efficiency of czech grammar schools. Czech Sociological Review, 45(6), 1265-1282.

Fuentes, R. (2011). Efficiency of travel agencies: A case study of Alicante, Spain. Tourism Management, 32(1), 75-87. 
Giménez, V., Prior, D., \& Thieme, C. (2007). Technical efficiency, managerial efficiency and objective-setting in the educational system: An international comparison. Journal of the Operational Research Society, 58, 996-1007.

Gray, J., Jesson, D., \& Jones, B. (1986). The search for a fairer way of comparing schools' examination results. Research Papers in Education, 1, 91-122.

Hanushek, E. A. (1997). Assessing the effects of school resources on student performance: An update. Educational Evaluation and Policy Analysis, 19(2), 141-164.

Henderson, J.M., \& Quandt, R.E. (1971). Microeconomic Theory. A mathematical approach (2nd ed.). New York: McGraw-Hill.

Jesson D., Mayston D., \& Smith, P. (1987). Performance assessment in the education sector: educational and economic perspectives. Oxford Rev Education, 13, 249-266.

Johnes, J., \& Yu, L. (2008). Measuring the research performance of chinese higher education institutions using data envelopment analysis. China Economic Review, 19(4), 679-696.

Kantabutra, S., \& Tang, J. C. S. (2006). Urban-rural and size effects on school efficiency: The case of northern thailand. Leadership and Policy in Schools, 5(4), 355-377.

Kao, C., \& Hung, H. (2008). Efficiency analysis of university departments: An empirical study*. Omega : The International Journal of Management Science, 36, 653-664.

Kim, D., Zabel, J., Stiefel, L., \& Schwartz, A. (2006). School efficiency and student subgroups: Is a good school good for everyone? Peabody Journal of Education, 81(4), 95-117.

Lavado, R. F., \& Cabanda, E. C. (2009). The efficiency of health and education expenditures in the philippines. Central European Journal of Operations Research CEJOR, 17(3), 275-291.

Mancebón Torrubia, M. J., \& Muñiz Perez, M. A. (2008). Private versus public high schools in Spain: Disentangling managerial and programme efficiencies. Journal of the Operational Research Society, 59, 892-901.

Martin, E. (2006). Efficiency and quality in the current higher education context in europe: An application of the data envelopment analysis methodology to performance assessment of departments within the university of zaragoza. Quality in Higher Education, 12(1), 57-79.

Meeusen,W.,\& van den Broeck, J.(1977). Efficiency estimation from Cobb-Douglas production functions with composed error. International Economic Review, 18(2), 435-444.

Murias, P., de Miguel, J. C., \& Rodríguez, D. (2008). A composite indicator for university quality assessment: The case of spanish higher education system. Social Indicators Research, 89(1), 129-146.

Murillo-Melchor, C. Pastor, J.M., \& Tortosa-Ausina, E. (2010). A bootstrap approach to analyse productivity growth in European banking. Journal of the Operational Research Society 61, 1729 -1745.

Naper, L. R. (2010). Teacher hiring practices and educational efficiency. Economics of Education Review, 29(4), 658-668.

Oliveira, M. A., \& Santos, C. (2005). Assessing school efficiency in portugal using FDH and bootstrapping. Applied Economics, 37(8), 957-968. doi:10.1080/00036840500061095

Ouellette, P., \& Vierstraete, V. (2010). Malmquist indexes with quasi-fixed inputs: An application to school districts in qu,bec. Annals of Operations Research, 173(1), 57-76. doi:10.1007/s10479-008-0477-0

Ullah, A. (1999). Nonparametric Econometrics. Cambridge University Press. Cambridge

Portela, M. C. A. S., \& Thanassoulis, E. (2001). Decomposing school and school-type efficiency. European Journal of Operational Research, 132(2), 357-373.

Ray, S. C., \& Jeon, Y. (2008). Reputation and efficiency: A non-parametric assessment of america's top-rated MBA programs. European Journal of Operational Research, 189(1), 245-268.

Simar, L. \& Wilson, P. W. (2000) A general methodology for bootstrapping in nonparametric frontier models. Journal of Applied Statistics, 27, 779-802.

Spircu, L., Albu, C., Rosca, I. G., \& Serban, R. (2007). Educational process, a multi inputs and multi outputs process. Economic Computation and Economic Cybernetics Studies and Research, 41(1-2), 5-16.

Thanassoulis, E., \& Dunstan, P. (1994). Guiding schools to improved performance using data envelopment analysis: An illustration with data from a local education authority. The Journal of the Operational Research Society Houndmills, 45(11), 1247-1262.

Thanassoulis, E. (1996). Altering the bias in differential school effectiveness using data envelopment analysis. The Journal of the Operational Research Society Houndmills, 47(7), 882-894.

Thanassoulis, E., Kortelainen, M., Johnes, G., \& Johnes, J. (2011). Costs and efficiency of higher education institutions in england: A DEA analysis. The Journal of the Operational Research Society, 62(7), 1282-1297. doi: http://dx.doi.org/10.1057/jors.2010.68

Thieme, C.; Prior, D.; Giménez, V. \& Tortosa-Ausina, E. (2011). Desempeño de los centros educativos: ¿un problema de recursos 0 capacidades organizativas? Hacienda Pública Española / Revista de Economía Pública 199 (4), 81-118.

Tyagi, P., Yadav, S. P., \& Singh, S. P. (2009). Relative performance of academic departments using DEA with sensitivity analysis. Evaluation and Program Planning, 32(2), 168-177.

Wößmann, L. (2003). Schooling resources, educational institutions and student performance: The international evidence. Oxford Bulletin of Economics and Statistics, 65(2), 117-170.

Yuhong, D., \& Yongmei, H. (2008). Student academic performance and the allocation of school resources. Chinese Education and Society, 41(5), 8-20. doi:10.2753/CED1061-1932410501 